Euskal ikerketen aldizkaria | Revue d'études basques |

Revista de estudios vascos | Basque studies review

$13 \mid 2009$

Numéro XIII

\title{
Aldakiak eta aldaerak : Atxagaren Obabako amerikanoa
}

Joana Pochelu

\section{OpenEdition}

\section{Journals}

Édition électronique

URL : http://journals.openedition.org/lapurdum/2165

DOI : 10.4000/lapurdum.2165

ISSN : 1965-0655

Éditeur

IKER

Édition imprimée

Date de publication : 1 février 2009

Pagination : 297-303

ISBN : 978-2-86781-409-X

ISSN : $1273-3830$

Référence électronique

Joana Pochelu, «Aldakiak eta aldaerak : Atxagaren Obabako amerikanoa », Lapurdum [Linean]

13 | 2009, Sarean emana---an 15 avril 2013, kontsultatu 19 avril 2019. URL : http://

journals.openedition.org/lapurdum/2165; DOI : 10.4000/lapurdum.2165 


\title{
Aldakiak eta aldaerak: Atxagaren Obabako amerikanoa
}

\author{
Joana POCHELU \\ Michel de Montaigne Unibertsitatea - Bordeaux 3
}

\section{Laburpena :}

Artikulu honetan, MEDITE programa informatikoaren aplikazio bat proposatzen dugu, Atxagaren Soinujolearen semean den testu baten bitartez: Obabako lehen amerikanoa. Errealitatean oinarri duen pertsonaia horrek, testuan berean bi aldaki erakusten ditu, eta beste bat bi horietarik baten aitzin-testuan. Azken hau tapuskritoa edo ordenagailuz idatzitako izkribu bat da, MEDITE-k bere aldakiarekin konparatuko duena, ondotik honen genesia azter dezagun.

\section{Abstract :}

In this paper we propose an application of the MEDITE software to a narration included inside The Accordionist's Son (Bernardo Atxaga, 2003). The principal character presented in this narration, "the first American from Obaba", is based on reality and has two different versions in the text itself. One of these two versions has an avant-texte (a tapuscript) that we have analyzed thanks to MEDITE, comparing both versions and thus facilitating their genetic interpretation.

Hitz gakoak : MEDITE programa informatikoa; testuen genetika ; aldakiak.

Key words : MEDITE software; textual genetic ; versions.

Bernardo Atxagaren Soinujolearen Semea eleberrian (Pamiela, 2003) narrazio bat bada Obabako lehen amerikanoa deitua. Narrazio horrek eleberrian berean aldaki bat badu, eta aldaki horrek beste bertsio bat, idazlearen lan tapuskritoetan ${ }^{1}$ aurkitzen dena.

Kontaera honi esker, testu baten aldaki desberdinak MEDITE programa informatikoarekin nola trata daitezkeen ikusiko dugu, eta ondotik tresna hori gure narrazioari aplikatuko dugu bere idazketa prozesuaren ikertzeko.

\section{Amerikanoaren hiru aldaki}

Interesatzen gaituen testuaren hiru aldakiek pertsonaia nagusi bera dute ardatz : amerikanoa. Hiru aurpegi desberdin erakusten ditu, bi fikzioan eta beste bat errealitatean kokatuak. Lopez de Aranak argitaratu zuen artikulu batean" "Atxagaren Soinujolearen semea eleberriko don Pedro pertsonaiak, Obabako amerikanoak, Arabako Foru Aldundiko diputatu errepublikazale izandako

1. Ordenagailuko izkribuak.

2. I. Lopez de Arana, "Galarretako amerikanoa", Berria, 2004-02-01. 
Pedro Salinasen bizitzan du[ela] oinarria" adierazten zuen. Gomez Calvo-k ere artikulu bat ${ }^{3}$ idatzi zuen amerikanoaren bizia aipatuz, honen memorio argitaragabeetan oinarrituz.

Soinujolearen semean beraz, Atxagak Pedro Salinas Arregui, fikziozko pertsonai bilakarazi du bere narratzailearen (David) bitartez eta don Pedro izena eman dio.

Hirugarren aurpegia, hau ere fikziozkoa, amerikanoaren pertsonaiak idatzi aldakian agertzen da, baina aitzinekoaren gertakari bera da kontatua, lehen bertsioa bigarrenaren berridazketa baita. Davidek bere egunkarian dio:

Obabako lehen amerikanoaren idazkia nahi nuen, baina benetakoa, don Pedro Galarretak, nire osaba Juani oparitutako eskuizkributik kopiatu nuena. [...] Ipuinak oinarri bat zue[n], Obabako lehen amerikanoak berak idatzitako orri sorta bat, zeinetan fusilatu nahi izan zuteneko gaua kontatzen zuen. [...]. ${ }^{4}$

Daviden ustez "errealitatean, gauzak askozaz ere modu tristeagoan gertatu ziren". Bere pentsamendua zehazten du, "errealitatea tristea dela, eta liburuek, baita gogorrenek ere, edertu egiten dutela"s gehituz.

Errealitatea eta fikzioaren mugan dabil hemen Atxaga. Mari Jose Olaziregik Soinujolearen semea-ri buruzko artikulu batean ${ }^{6}$ zion bezala, Obabako lehen amerikanoa-ren aldakiak "literaturaren funtzioa bera hizpide duten narrazioak" zirela :

Soinujolearen semeak gertakari beraren bi aldaki eskaintzen dizkigu, literaturak errealitatearekin duen harremanaren inguruko hausnarketa metaliterario bat burutzeko : "errealitatea tristea da eta literaturak edertu egiten du”. Finean, Literatura eta Historia interpretazio bat eskaintzen duten diskurtso narratiboak besterik ez direla ohartarazi nahi digu narratzaileak. ${ }^{7}$

Pertsonaiaren hiru begitarteez gain, beste aldaki mota bat ere badugu Don Pedro Galarretak 1936ko abuztuaren 15ean gertatutakoa kontatzen du deitua den bigarren aldakiarentzat. Aitzin-testuaren eremuan kokatzen da, fikziozko aldakiaren bariantea da, eta aldi berean bere genesia. Ordenagailuz idatzitako testu egoeran aurkitzen da, baina honen sorrera aztertu baino lehen, aitzin-testu informatizatuak nola trata daitezkeen ikusiko dugu.

\section{MEDITE}

Dosier genetiko bat muntatu dugu amerikanoaren bi bertsio desberdinetaz osatua, baina Don Pedro Galarretak 1936ko abuztuaren 15ean gertatutakoa kontatzen du aitzin-testuari gara interesatuko hemen. Narrazioaren aitzin-testua ordenagailuz idatzitako testu egoeran dugu, ez da beraz usaian idazleen idazketa prozesua aztertzen delarik bezala eskuizkribu moduan azaltzen, baina tapuskrito gisa.

Baina ordenagailuan idatzirik ere, obra batek jatorri bat badu, genesia bat ezagutu du. Eta eskuz idazten duten ala zuten idazleek eta ordenagailuan idazten dutenek, berdin-berdin dokumentu mota desberdinak produzitu ditzakete, hala nola nota soilak, kapitulu bat, testu bukatuxe bat, bertsio

3. J. Gómez Calvo, "Historia de Galarreta : de la dictadura de Primo de Rivera a la guerra civil (1923-1939)", Sancho el Sabio, 27. zkia, 2007, 101-129. orr.

4. B. Atxaga, Soinujolearen semea, Iruñea : Pamiela, 2003, 460. orr.

5. Ibid., 465. orr.

6. M.J Olaziregi, "Paradisua... hemen", Landázuri elkartea, 11-12-13. zenbakiak, 2005eko abendua. http://www.landazuri.com/es/revista.asp (2009-01-28an ikusia).

7. Ibid. 
desberdinak... Desberdintasun bakarra : ukanik ere, tapuskritoek ez dutela egoera desberdinak ikusten uzten.

Beti ere, teknologia berriek aitzinkada lasterra ezagutzen dute. Eta beraz idazketa eta euskarri ohiturak aldatzen badira, haien erabiltzeko eta aztertzeko tresnak ere berehala (edo kasik berehala) agertzen dira.

Filologoak laguntzeko xedez, eta genesiaren interpretaketaren errexteko, MEDITE (Machine d'Etude Diachronique et Interprétative du Travail de l'Ecrivain) ${ }^{8}$ asmatua izan da. Hain zuzen ere, programa horrek lanaren aitzin-urratsa egiten du, testu baten bi bertsioren artean zer pasatzen den argiki adieraziz bere interfazeari esker. Programak automatikoki kenketak, gehiketak, aldaketak eta mugimendu guziak bereizten ditu. Lana errexten eta denbora irabazten da MEDITE-i esker. Gainera, aldaketa guztiak sistematikoki eta zehazki taula batean idatzirik agertzen dira.

Emaitza horren ukaiteko, MEDITE programan testu baten bertsio desberdinak sartu behar dira, (Microsoft Office-eko "Bloc-notes" formatuan) eta gero "exécuter MEDITE" botoia sakatu. ${ }^{9}$ Hor, programaren aplikazioa agertzen zaigu, bi bertsioen arteko aldaketa guziekin. Taularen azpikaldean lau leiho desberdin ikusten dira: alde batetik, leienda batek hiru kolore erakusten ditu (erabiltzaileak bere gustura hautatzen ahal dituenak). Gure kasuan, berdeak gehiketak adierazten ditu, gorriak kenketak, eta ubelak ordezketak - toki aldaketak azpimarratze batekin markatuak direlarik. Beste leiho batek, transformatze guzien zerrenda agerian jartzen du, hirugarren leiho batek ikerleari komentarioen idazteko parada uzten diolarik. ${ }^{10}$ Hona hemen gure aitzin-testua eta testua osoki sartu eta, MEDITE-ek erakustera ematen diguna:

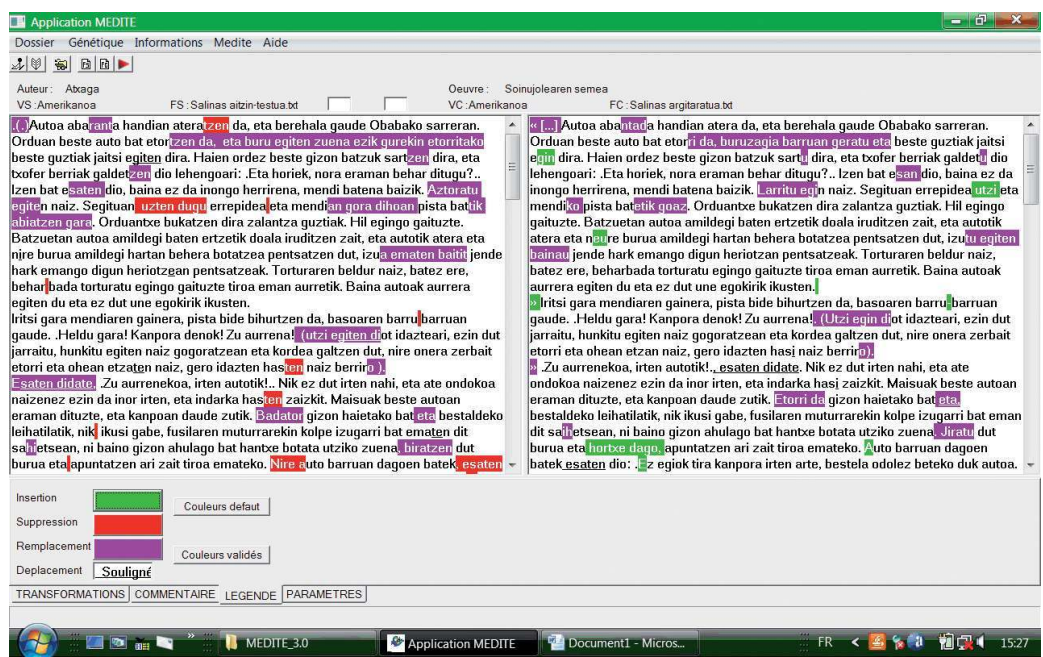

8. J. G. Ganascia, I. Fenoglio, J-L. Lebrave, "Manuscrits, genèse et documents numérisés. EDITE : une étude informatisée du travail de l'écrivain”, Revue Document numérique. Temps et documents, vol.8, n4 (p. 91110).

9. Dosier genetikoa eskuizkribuz osatua denean ere egin daiteke, baina bistan den bezala, lehenik testua ordenagailuan jo behar da.

10. Laugarren leihoak programaren parametro zenbait aldatzeko aukera ematen du. Ikus beherago. 

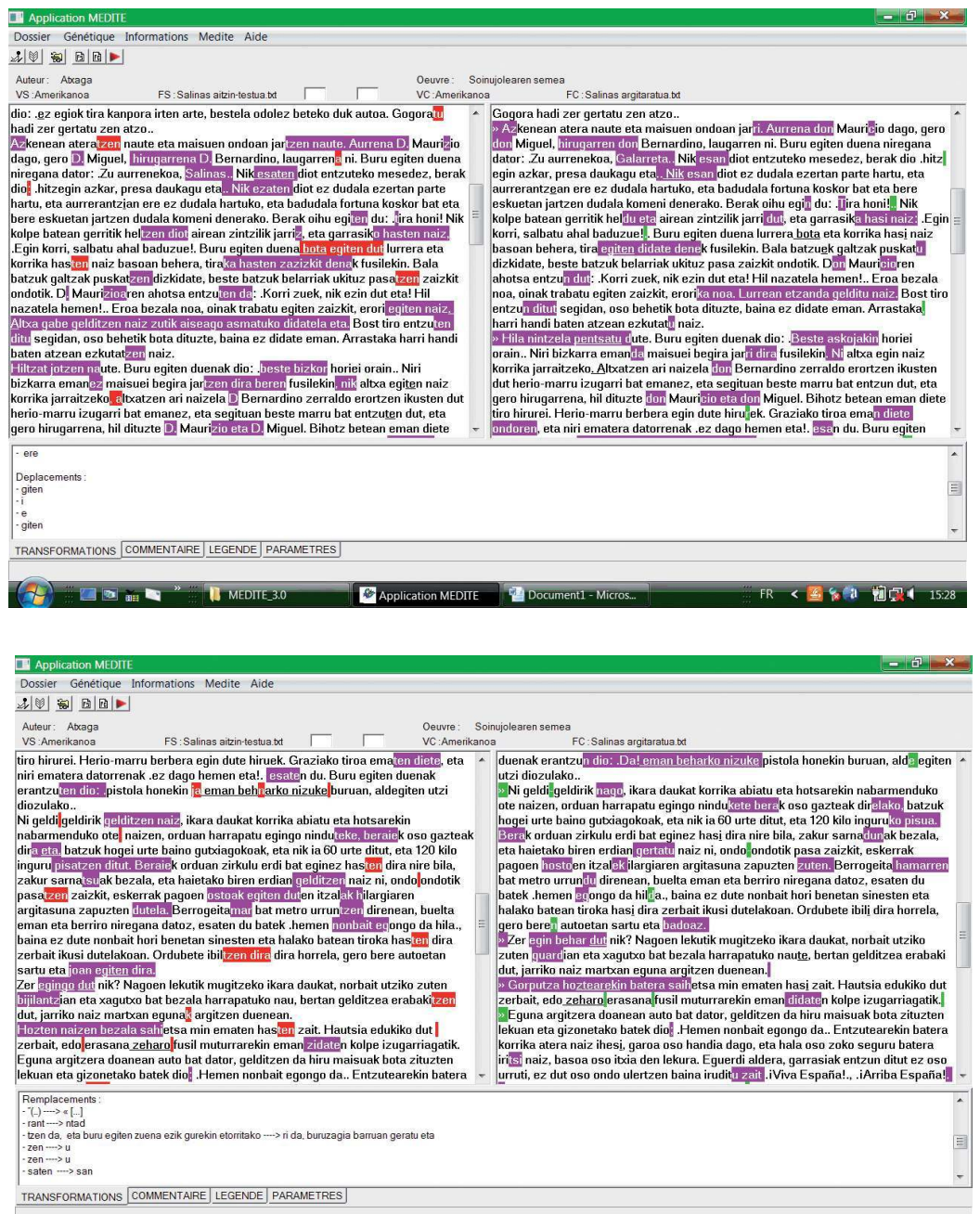

trANSFORMATIONS COMMENTAREL LEGENDE] PARAMETRES

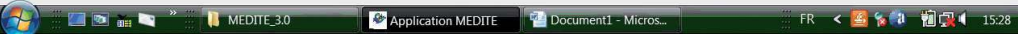

Programa honi esker, kantitate handiko piezak trata daitezke. Zenbaitetan, begi hutsez ikusiko ez genuen detaile garrantzitsu batez ohartzeko parada eman dezake. Bestalde, idazlanari buruz estatistikak egiteko, autoreak egiten dituen aldaketa moten karakterizatzeko etab, posibilitatea ematen du. ${ }^{11}$ Lan hori egin eta, ikerlariari idazketa prozesuaren interpretatzea "baizik" ez zaio gelditzen.

11. Beste tresna informatiko batek ere (euskal literaturari lotua) lagun gaitzake tapuskritoetatik ateratzen ditugun estatistikak behin betiko testuarekin konparatzeko. Hau da, Interneten aurki daitekeen EPG (Ereduzko Prosa Gaur) programak hitz bat edo espresio bat zein tokitan, zenbat aldiz, eta zein testuingurutan agertzen den ikusteko aukera ematen du. Corpusean dauden testuen artean Soinujolearen semea aurkitzen da. 

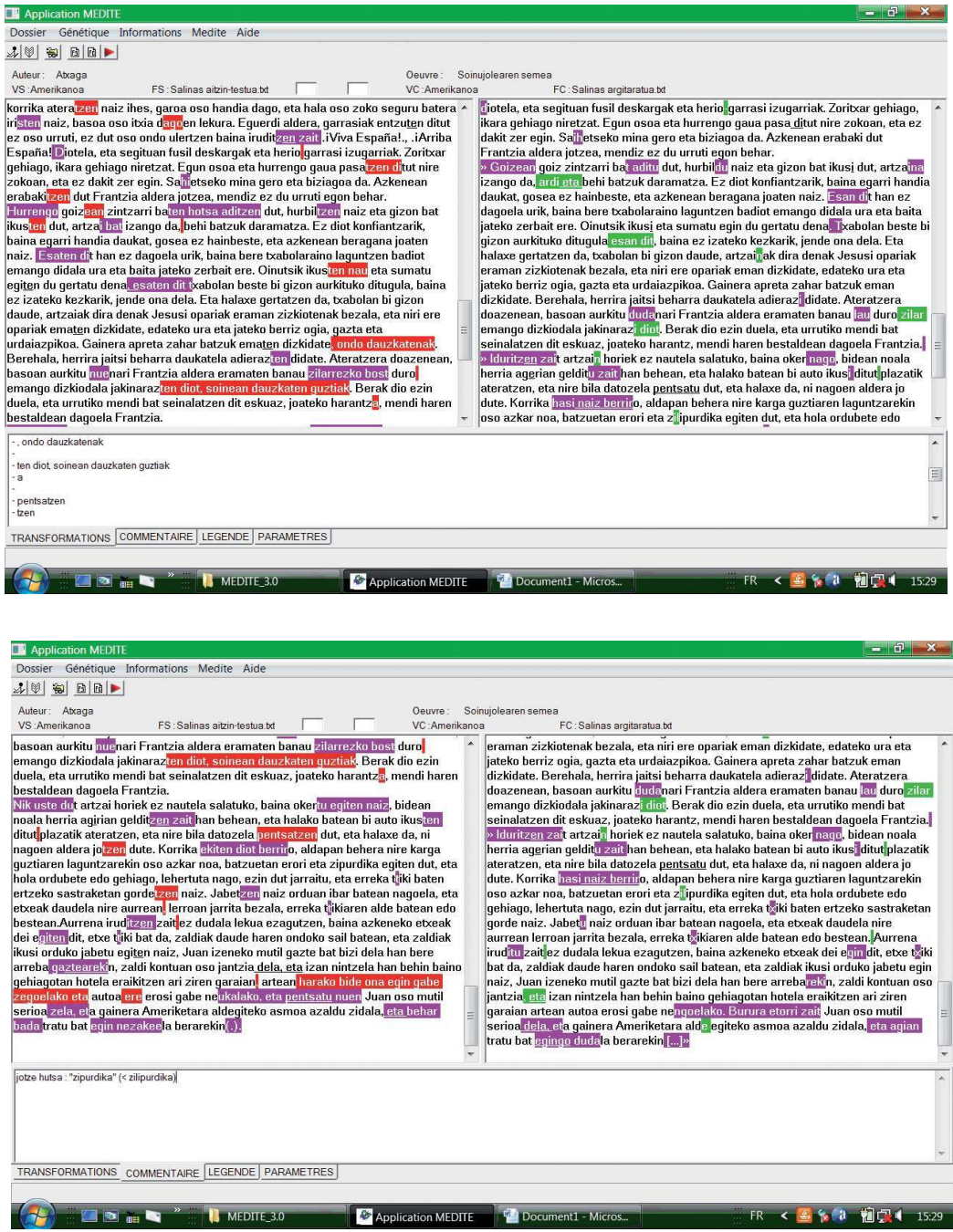

\section{Narrazioaren genesia}

Gaineko bost taulek erakusten digute argitaratu testua eta honen aitzin-testuaren artean gertatu den guzia. Ikus daitekeen bezala, azken erabakiak ez dira oraindik hartuak, baina testua jadanik kasik "bukatua" da, kasik bere azken formaren itxura du. Halere, testuak aldaketa zenbait ezagutu ditu, forma aldetik bereziki.

Lehenbizikorik agertzen den aldaketa bat, narrazioaren denborarena da. Hau da, narrazioak galdegiten dituen arauen jarraikitzeko, lehen bertsioan agertzen zen aspektu ez burutua, orainaldiko aspektu burutu bihurtzen da. Ondorioz ere, aditz trinkoak, aditz perifrastiko bilakarazi behar izan ditu Atxagak. Honela, lehen aldakiko "ateratzen da", "atera da" aditzak ordezten du bigarrenean, "hasten naiz", "hasi naiz"-ek, edo "badator" aditz trinkoa, "etorri da" aditz perifrastikoak.

Beste ordezketa batzu ere egin ditu idazleak, testua tonu aldetik egokiago gelditzeko. Esate 
baterako, "buru egiten zuena" "buruzagia" bihurtzen da, eta "bijilantzian" hitzaren ordez "guardian" ezarria da. Idazleari hiztegi militarra komenigarriagoa zitzaion gertakaria bere testuinguruan argiki finkatzeko, eta bi aldaketa hauek xede horrekin egin dituzke. Buruzagiak preseski, lehen bertsioan fusilatzeko tenorean, "beste bizkor horiei" dela adierazten du ; bigarren aldakian "beste askojakin horiei" delarik. Hiztegi peioratiboagoa nahiago izan du autoreak, aldi honetan ere, tonua istorioan iragaten denarekin bat etor zedin.

Bestalde, don Pedro Galarreta aurkitzen den egoeraren ahulezia azpimarratzeko, aldaketak izan dira aitzin-testu eta testuaren artean. Lehen bertsioan, lasterka eskapatuta, erortzen da, eta "altxa gabe gelditzen [da]", bigarren bertsioan haatik, "lurrean etzanda gelditu [da]". Aitzineko aldakian, pertsonaiak berak du erabakitzen altxa gabe egotea, badu oraindik botere bat ; baina lurrean etzanda denean, hor zaurgarriagoa agertzen da, ez da gehiago gertatzen denaren jabe. Kasu bera ikus daiteke beherago, "hozten naizen bezala" ordezkatzen duenean, "gorputza hoztearekin bezala" ezartzeko. Berriz ere gorputzaren mendretasuna markatu nahi du idazleak, pertsonaiak memento horretan bizi duen perila.

Azkenik, Atxagak zuzenketa ortografiko eta gramatikoak egin ditu. Adibidez, izen batzuen idazkera aldatu du, hala nola "D. Maurizio" "don Mauricio" bihurtu da, eta "D. Bernardino" "don Bernardino". Edo ere, ortografia faltak zuzendu ditu : "osto"-ri falta zitzaion "h"-a gehitua izan zitzako, "hilargi"-ari kendua, eta "sahietsa"-ri tokiz aldatua (saihetsa). Euskaltzaindiaren arauen arabera batuak onartzen duen forma ezarri du, "ttiki" izenlagunarentzat alegia, "txiki"-z ordezkatu du. Edo ere, ordinalari artikulua kendu dio, zenbaketa zerrenda batean zelako : "Aurrena D. Maurizio dago, gero D. Miguel, hirugarrena D. Bernardino, laugarrena ni." Hots, "hirugarren" eta "laugarren" agertzen da bigarren bertsioan.

Ordezketa arraro bat ere ikus daiteke bi barianteen artean. Arraro, ez baitakigu zein arrazoiengatik Galarretak artzainari lehenik "zilarrezko bost duro" eman nahi dizkion eta ondoko aldakian "lau duro zilar". Zergatik kopuru aldaketa hori ? Funtsean bederen, ez du deus berririk ekartzen.

Azkenik, peto ttipi bat aipatu behar dugu : gorago erran bezala, narrazio honetan amerikanoa don Pedro Galarreta deitzen da. Baina hiru amerikano desberdin horien artean, autorea galdu egiten da eta aitzin-testuan aldi batez "Salinas" izendatzen du. Baina testuan zuzendua da, eta berriz ere "Galarreta" deitzen da, narrazio horri doakion bezala.

Bi bertsioen arteko aldaketa guzi hauek argiki agertarazi ditu beraz MEDITE programak. Halere mugatuak gira euskarazko testuak konparatzeko mementoan, programa frantses hizkuntzarentzat parametratua izan baita. Esaterako, bertsio batetik bestera "egiten", "egin" bihurtzen delarik, -gin gehiketa bezala kontsideratua da eta ez ordezketa gisa. Gauza bera "uzten" eta "utzi”-rekin : "utzi" gehiketa moduan erakutsia da, ez aldaketa bat balitz bezala. Gero, "zilar", gehiketa eran emana da, alta "zilarrezko" ordezketa eran. Eta, "pentsatzen" kenketa bat da, "pentsatu" mugitze bat delarik. Segurki, frantsesez ere muga zenbait ditu programak, berria delako, genetikari eta informatikarien artean oraindik hobetzen ari baita, beraz ez da dena arras ponduan; baina zinez interesgarri liteke euskal ikerketaren arloarentzat norbaitek euskararentzat parametra baleza...

Informatika gaur egungo gizartean sartua da, denen ohituretan finkatua da, ondorioz, literatura ikerketak - eta are gehiago euskal literaturarenak - ez du teknologia berri horien beldur ukan behar, alderantziz, treina martxan hartu behar du.

\section{Bibliografia :}

Ganascia, Jean-Gabriel, Fenoglio, Irène, Lebrave, Jean-Louis, "Manuscrits, genèse et documents numérisés. EDITE : une étude informatisée du travail de l'écrivain”, Revue Document numérique. 
Temps et documents, vol.8, nº (p. 91-110).

Gómez Calvo, Javier, "Historia de Galarreta : de la dictadura de Primo de Rivera a la guerra civil (1923-1939)", Sancho el Sabio, 27. zkia, 2007, 101-129. orr.

Lopez de Arana, Inaxio, "Galarretako amerikanoa", Berria, 2004-02-01.

Olaziregi, Mari-Jose, "Paradisua... hemen", Landázuri elkartea, 11-12-13. zenbakiak, 2005eko abendua.

Pochelu, Joana, "A propos de ma thèse. Où on parle (toujours) de génétique textuelle...", Lapurdum, XI, Baiona : IKER-UMR 5478, 2006, 305-309 orr. 